\title{
BUDAYA DAN FUNGSI DALAM LEGENDA GUA TAN TIK SIU DI DESA SUMBERAGUNG KECAMATAN REJOTANGAN KABUPATEN TULUNGAGUNG
}

\author{
Tsalits Abdul Aziz Alfarisi \\ Kiki Astrea \\ Universitas Islam Darul Ulum Lamongan (UNISDA) \\ drumbig_tsalis@yahoo.co.id
}

\begin{abstract}
Literature is an expression of feeling and of thought written by contextual value of a language. It refers to the concept of oral or folk literature which includes the literature expression of society's culture passed on upon descend and through spoken word. The legend of Tan Tik Siu cave is one of oral literature originated from Tulungagung which grew and expanded in Sumberagung village Rejotangan subdistrict. The originality and cultural value of the phenomenon are feasible to investigate due to its uniqueness. There is a cycle when the society should and should not do some rituals in the cave. Thus, they should not do the ritual every day. It is believed that there will be a danger for Sumberagung villagers whenever they break the conviction. The problem of the study focused on how are the cultural values and its functions for the society. A descriptive qualitative approach is employed through observation, interview, audiorecording and note-taking. The analysis of cultural value suggested four kinds of cultural values including: (1) magic value, especially the society's belief on pesugihan la particular magic, (2) behavior value applied to the surrounding society, and (3) religious value. The result function analysis found four kinds of functions which cover: (1) projection system as a one's thoughts on the future doing, (2) validation instrument of cultural research organization (3) education instrument (4) entertainment instrument
\end{abstract}

Keywords: Legend, Tan Tik Siu cave, Cultural value and its function

\begin{abstract}
Abstrak: Sastra merupakan ekspresi pikiran perasaan yang ditulis dengan menggunakan bahasa sesuai dengan nilai konteksnya. Hal tersebut merujuk kepada konsep sastra lisan dimana kesastraan yang mencakup ekspresi kesastraan warga suatu kebudayaan yang disebarkan dan diturunkan turun temurun secara lisan dari mulut ke mulut. Salah satu bentuk sastra lisan di Tulungagung yang tumbuh dan berkembang di desa Sumberagung kecamatan Rejotangan adalah legenda Gua Tan Tik Siu. Hal tersebut menarik untuk diteliti karena nilai budaya legenda Gua Tan Tik Siu merupakan fenomena yang cukup baru bagi peneliti. Mengapa demikian, karena legenda Tan Tik Siu memiliki siklus tertentu bagi masyarakat yang ingin menjalankan ritual di tempat tersebut. Tidak setiap hari orang dapat menjalankan ritual. Jika hal tersebut dilanggar maka kepercayaan masyarakat disana sepakat akan ada marabahaya yang siap menimpa masyarakat di daerah Sumberagung. Penelitian Legenda Gua Tan Tik Siu mengangkat permasalahan mengenai bagaimana nilai budaya, dan fungsi bagi masyarakat pendukungnya. Pendekatan dalam penelitian ini menggunakan pendekatan deskriptif kualitatif dengan cara pengamatan, wawancara, perekaman dan pencatatan. Analisis nilai budaya Legenda Gua Tan Tik Siu ada empat macam, meliputi: (1) Nilai Kepercayaan masyarakat terhadap pesugihan dan keajaiban
\end{abstract}


tertentu, (2) Nilai Tingkah Laku yang berlaku bagi masyarakat sekitar, (3) Nilai religi. Analisis fungsi Legenda Gua Tan Tik Siu ada empat, yaitu (1) Sistem Proyeksi adalah angan-angan seseorang tentang apa yang akan dilakukannya, (2) Pengesahan pranata cara dan Lembaga Kebudayaan, (3) Alat Pendidikan, dan (4) Alat Hiburan.

\section{Kata Kunci: Legenda, Gua Tan Tik Siu, nilai kebudayaan dan fungsi}

\section{PENDAHULUAN}

Masyarakat Indonesia mempunyai keanekaragaman yang dilatarbelakangi oleh keadaan budaya, agama, dan kepercayaan yang berbeda-beda. Hal tersebut merupakan warisan leluhur yang tidak ternilai dan patut dibanggakan. Salah satu contoh kebudayaan nasional bangsa Indonesia adalah sastra. Sastra merupakan ekspresi pikiran perasaan maupun tulisan menggunakan bahasa yang indah menurut konteksnya (Hutomo, 1997:39). Sastra lisan yaitu kesastraan yang mencakup ekspresi kesastraan warga suatu kebudayaan yang disebarkan dan diturunkan turun-temurun secara lisan dari mulut-ke mulut (Hutomo, 1991:1). Sastra lisan merupakan warisan budaya daerah turun-temurun yang dapat dikembangkan juga dimanfaatkan serta mempunyai nilai-nilai luhur yang cukup tinggi dalam hubungan usaha pembinaan dan pencintaan sastra.

Anggapan sastra dapat berfungsi sebagai suatu perkembangan bahasa daerah dan juga pengungkapan alam pikiran dan nilai-nilai kebudayaan (Danandjaya, 1991:1) jelas bahwa sastra lisan tersebut mempunyai kedudukan dan fungsi yang penting sehingga sastra lisan perlu disematkan, dipelihara dan dikembangkan. Sastra lisan lahir dan berkembang di masyarakat, namun keberadaan sastra lisan lebih sulit dipertahankan. Hal itu karena sastra lisan lahir pada masyarakat tradisional, masyarakat yang hanya memanfaatkan komunikasi lisan sebagai alat yang bergantung kepada ingatan penutur. Dalam masyarakat tradisional, peranan sastra lisan sangat besar dari pada sastra tulis. Sastra lisan menjadi identitas primer bagi masyarakat perorangan maupun kelompok.

Masyarakat

Sumberagung,

Kecamatan Rejotangan Kabupaten Tulungagung adalah masyarakat yang memiliki sikap hidup berdasarkan adat istiadat tata cara leluhur sejak berabadabad lamanya, meskipun adat istiadat itu secara logika tidak masuk akal. Adat tersebut misalnya mengenai kepercayaan pada hal-hal gaib. Jalan pikiran semacam ini menimbulkan sikap hidup yang berusaha untuk selalu mengikat dirinya dengan sengaja kekuatan yang mempunyai pengaruh kehidupan seharihari. Jadi, dapat dikatakan bahwa setiap kelompok masyarakat membentuk kesadaran sejarah atau ingatan mengenai masa lampau sebagai legenda.

Penuturan di atas menjadi alasan mengapa peneliti mengadakan penelitian tentang Legenda Goa Tan Tik Siu di Sumberagung, Rejotangan, Tulungagung dengan menggunakan analisis nilai budaya, dan fungsi. Diharapakan dengan adanya penelitian ini dapat membangkitkan semangat generasi muda yang lain terhadap sejarah kebudayaan suatu daerah agar tidak punah dimakan oleh perkembangan zaman.

\section{METODE PENELITIAN}

Metode dalam penelitian ini menggunakan deskriptif kualitatif. Pada penerapannya, metode ini membaca teks yang berasal dari salinan (transkripsi) wawancara yang direkam melalui alat perekam kemudian disalin dalam bentuk teks (Endraswara, 2003: 38). Kemudian peneliti mencatat teks-teks yang 
berkaitan dengan nilai budaya, fungsi dimana teks-teks tersebut pada awalnya di kelompokkan satu persatu yang bertujuan untuk menemukan identitas budaya dan fungsi. Penentuan informan dalam penelitian ini memfokuskan diri pada informan yang diperoleh dari petunjuk kepala desa setempat. Hal tersebut diperlukan mengingat banyaknya informan yang sedikit banyak memahami legenda Tan Tik Siu. Teknik pengumpulan data dalam penelitian ini menggunakan teknik observasi dimana peneliti secara langsung survey lapangan kemudian mewawancarai informan yang sudah peneliti tentukan dan mempersiapkan instrumen perekaman (Sudikan, 2001: 27).

Hasil perekaman dalam penelitian ini merupakan hasil yang menggunakan bahasa asli yaitu beberapa naskah dan wawancara menggunakan bahasa Jawa dan jawa kuno (untuk naskah). Dalam hal ini peneliti menggunakan terjemahan literal yang bertujuan agar teks dapat dibaca dan dimengerti tanpa mengubah konteks aslinya (Sudikan, 2001: 27).

\section{PEMBAHASAN DAN PAPARAN DATA}

Asal usul cerita berdirinya Goa tersebut, yaitu ketika pangeran Papak (Tan Tik Siu) kecil yang ikut para orang tua mengembala. Ketika waktu pagi dan sore anak tersebut ada, tetapi selain waktu tersebut ada itu tidak ada. Dia menyuruh warga sekitar desa Sumberagung untuk mencari batu sebagai bahan bangunan goa, dan selama tiga tahun lamanya akhirnya masyarakat berhasil mengumpulkan batu tersebut dan cukup untuk membangun sebuah Goa buatan (Goa Tan Tik Siu).

Menurut sejarah, Desa Sumberagung merupakan salah satu wilayah yang mempunyai lima sumber mata air besar. Sumber tersebut yaitu sumber klampok, sumber banger, sumber urip, dan sumber ece. Ketika pada jaman dahulu kala desa Sumberagung merupakan sebuah rawa besar, dan oleh simbah Tan Tik Siu kelima sumber tersebut ditutup menggunakan sapu lidi (sadha) dan ada juga yang ditutup menggunakan uang logam (ece, ece merupakan uang jaman dahulu kala dan 1 ece sama seperti RP 1/100) yang berjumlah empat kaleng (bleg).

Desa Sumberagung menyimpan peninggalan di jaman dahulu kala seperti Goa Tan Tik Siu yang mempunyai lebar $10 \mathrm{~m}$, dan panjang $12 \mathrm{~m}$ (informan Pak Jaya Sirin) yang terletak di desa Sumberagung Kecamatan Rejotangan Kabupaten Tulungagung.

Desa Sumberagung Kecamatan Rejotangan Kabupaten Tulungagung Provinsi Jawa Timur, mempunyai batasan Desa yaiku sebelah utara berbatasan dengan Desa Rejotangan Kecamatan Rejotangan, sebelah selatan berbatasan dengan Desa Sumberejo Kecamatan Kademangan, Sebelah barat berbatasan dengan Desa Tanen dan Desa Blimbing Kecamatan Rejotangan, sebelat timur berbatasan dengan Desa Jimbe, Desa Plumpung Rejo Kecamatan Kademangan Kabupaten Blitar (Sumber data monografi desa Sumberagung 2018).

Masyarakat Sumberagung mayoritas beragama islam, tetapi masyarakat desa Sumberagung juga ada yang percaya dengan kekuatan ghaib seperti mencari berkah di Goa Tan Tik Siu. Masyarakat desa Sumberagung juga ada yang beragama kejawen, maksudnya islam kejawen yaitu masyarakat yang menjalankan ajaran agama islam, tetapi tidak sepenuhnya. Karena, masyarakat tidak bisa lepas begitu saja dengan tradisi leluhur yang sangat di junjung tinggi oleh nenek moyang mereka.

Tan Tik Siu lahir di Surabaya sekitar tahun 1884. Beliau memiliki riwayat penyakit autisme. Karena penyakit tersebut dia terkucilkan oleh keluarganya. Dia pergi meninggalkan 
rumah merantau sampai di desa sumber agung dan mempunyai bapak angkat bernama Pak Budiman. Zaman dahulu Tan Tik Siu membangun Gua yang bernama Tan Tik Siu di desa Sumberagung yang merupakan Goa nomor dua. Sedangkan gua yang pertama ada di Arga Khayangan Wilis Sendang Tulungagung.

Cerita yang terdapat di Gua tersebut yaitu kisah pangeran Papak (nama lain Tan Tik Siu) yang ikut mengembala bersama orang-orang lainnya. Pada suatu sore tidak terlihat sosok bocah tersebut, namun setiap pagi anak itu selalu muncul. Oleh masyarakat desa Sumberagung dia disuruh mencari batu selebar satu meter dan tinggi satu meter (1 kibek). Setelah itu Tan Tik Siu pergi ke Arga Wilis Sendang Tulungagung beliau membuat Gua di sana, itu merupakan goa pertama yang di buat oleh Tan Tik Siu dan setelah jadi, tiga bula kemudian Tan Tik Siu membuat Goa kedua yang ada di Desa Sumberagung, Kec. Rejotangan, Kab. Tulungagung.

Tan Tik Siu sering mengadakan hiburan berupa jaranan, wayang di Desa Sumberagung. Setelah tinggal beberapa taun di desa Sumberagung Tan Tik Siu sering di minta tolong masyarakat sekitar datang kesana untuk meminta obat, dan pesugihan. Keajaiban beliau adalah dapat mengubah loloan (pasir, gamping, batu) menjadi nasi, daun di ubah menjadi rokok dan uang. Goa Tan Tik Siu biasanya di gunakan masyakarat sekitar dan luar daerah untuk bertapa mencari mencari pesugihan.

Maka dari itu Goa ini berfungsi bertapa Goa Tan Tik Siu. Goa tersebut berdiri tahun 1921, dan di peruntuhkan untuk masyarakat desa Sumberagung. Selain bertapa, Tan Tik Siu mempunyai pekerjaan jualan capil (topi yang terbuat dari bambu). Dan uniknya capil tersebut di beri warna seperti bedera belanda merah, putih, dan biru. Bangsa Belanda marah karena Tan Tik Siu berkata "ayo bangsa belanda kalau berani kesinia", banjur bangsa Belanda datang ke Desa Sumberagung membawa bala tentara beberapa truck dan membawa perlengkapan perang lengkap. Melihat kedatangan bangsa Belanda, Tan Tik Siu membuat batu bata yang digunakan untuk melempari bangsa Belanda. Dan kejadian itu membuat bangsa belanda jera datang lagi di desa Sumberagung.

Tan Tik Siu oleh masyarakat desa Sumberagung di panggil limpah (wali), suhu Tan Tik Siu (Pangeran Papak). Sehari-hari kegiatan beliau adalah bertapa brata tanpa makan dan minum. Di depan Goa terdapat patung macan jumlahnya ada tiga, patung macan ini mempunyai cerita pada jaman dulu mbah Tan Tik Siu berteman atau lebih tepatnya bersaudara dengan Ratu Kidhul. Ketika Nyai Rara Kidhul datang ke Goa selalu menjelma menjadi macan. Maka, untuk mengenang bersaudaraan dengan beliau di buatlah patung macan tersebut.

Selain patung macan juga terdapat rumah-rumahan di Goa Tan Tik Siu yang berbentuk 45 maksudnya adalah bantengbanteng berjumlah 9 dan juga terdapat lambang-lambang kehidupan yang harus dipatuhi yaitu manusia itu tidak boleh sombong, berbicara buruk,berisik/gaduh, berzina dsb. Gandha mayit mempunyai arti manusia itu tidak ada yang suci semuanya kotor, kenapa di sebut manusia itu kotor karena kalau di lihat secara kasat mata manusia itu keluar lewat barang yang kotor (vagina), masuk ke dalam Goa tersebut manusia harus seperti orang meninggal tidak di lihat cantik/ganteng atau jelek.

Siapa saja yang kuat seperti Tan Tik Siu bakal mengetahui apa sebenarnya kehidupan itu. Selain itu, juga ada lagi ondhak-ondhakan (tingkatan) yang mempunyai nama Pagoda. Merupakan lambang tataran kehidupan bahwa seperti 
wali yang berjumlah sembilan dan siapa saja yang bisa melakukan kehidupan seperti simbol itu akan hidup makmur dan sejahtera karena sembilan adalah simbol Raja, siapa saja yang bisa melakukan kehidupan seperti itu bakal terkabul keinginannya. Goa Tan Tik Siu menghadap ke barat mempunyai arti bahwa sebelum ada masjid di bangun di daerah Sumberagung, Goa tersebut sudah si bangun menghadap ke kiblat.

Sedangkan Pagoda mempunyai jumlah sembilan tinggi menjulang dan terdapat mahkota mempunyai lambang Raja. Di dekatnya Pagoda ada genthong Sanepa mempunyai fungsi kaalau masyaraakat sekitar ada yaang sakit air genthong tersebutlah yang di gunakan sebagai obat. Selain itu juga terdapat sogi, di daerah inilah mbah Tan Tik Siu sering membakar dirinya menggunakan kertas dan bensin. Keajaiban pun terjadi, setelah di bakar bukannya mati atau luka-luka tubuh beliau malah berubah menjadi semakin muda. Untuk mengabadikan wajah Tan Tik Siu, di dalam goa di pasang foto beliau di lengkapi dengan jamsi (kotakan kecil yang berisi 1 sampai 37) isinya mengenai doa-doa atau ramalan. Caranya dengan mengocok jamsi tersebut kan di keluarkan 1 saja jamsi lalu di bacakan dan di cocokan dengan isi kotakan 1 sampai 37 tadi.

Orang yang mempercayai ramalan tersebut akan terkabul apa yang di inginkan, tetapi kalau tidak percaya tidak akan terwujud apa yang di inginkan. Di sekitar goa Tan Tik Siu terdapat pohon asem yaang tinggi dan besar, patung dewi kuan'im, dan patung jaran. Tata krama bagi siapa saja yang daatang ke goa Tan Tik Siu harus permisi ke beliau dulu dan kalau pulang juga harus berpamitan ke mbah Tan Tik Siu.

Siapa saja yang ingin berkunjung ke goa Tan Tik Siu harus membawa sesajen seperti jeruk, apel, roti, gula aren, lilin, dupa dsb. Di depan goa ada pohon dewa daru, siapa saja orang yang ingin kaya harus duduk di bawah pohon dewa daru sampai kejatuhan buahnya maka orang tersebut akan kaya. Akhir cerita simbah Tan Tik Siu di makamkan Pulau Pinang di malaysia.

\section{Nilai Budaya}

Menurut hasil penelitian ini, peneliti memiliki kesimpulan bahwa legenda Gua Tan Tik Siu memiliki tiga nilai budaya yaitu: 1) nilai kepercayaan, 2) nilai tingkah laku, 3) nilai abstraksi dari pengalaman tertentu, dan 4) nilai kehidupan masyarakat Sumberragung. Dalam nilai kepercayaan yang dialami oleh masyarakat Sumberagung ketika masuk Gua Tan Tik Siu dipercayai bisa mengaalami keberuntungan (sukses). Kejadian tersebut yang menjadikan seseorang memiliki niat yang sangat besar untuk memasuki Gua Tan Tik Siu. Kepercayaan tersebut dipercayai oleh masyarakat sekitar dan juga daerah lain. Kejadian tersebut dapat dilihat dari hasil wawancara peneliti oleh informan sebagai berikut:

"menurut mbah Andhen, si mbah Tan Tik Siu tidak meninggal. Tetapi mbah Andhen sendiri tidak mengerti dimana Tan Tik Siu sekarang berada. Sekarang banyak sekali warga sekitar atau luar daerah datang untuk mengalap berkah di Gua Tan Tik Siu misalnya orang yang usahanya bangkrut, ingin lancar sekolah, ingin mendapat jodoh dsb, karena di Gua Tan Tik Siu dipercayai tidak dimintai tumbal sama sekali" (wawancara dengan mbah Andhen 12 Mei 2016).

Penjelasan tersebut merupakan cerita dari Mbah Andhen mengenai banyaknya masyarakat yang datang ke Gua Tan Tik Siu. Semua masyarakat percaya bahwa semua orang yang mengalap berkah bakal berhasil. Maka dari itu Gua Tersebut tidak pernah sepi didatangi masyarakat yang ingin ngalap berkah. Maka di dalam Gua terdapat patung dewi Kuan Im. Penjelasan 
tersebut dapat dibaca dari wawancara berikut:

"didalam Gua Tan Tik Siu ada patung dewi Kuan Im, maksudnya adalah orang yang masuk Gua Tan Tik Siu harus melakukan dan yang terakhir berpamitan kepada Tan Tik Siu. Siapa yang memiliki keinginan datang ke Gua Tan Tik Siu harus membawa sesajen seperti jeruk, apel, roti, dsb. (wawancara dengan Mbah Salam, 12 Mei 2016)

Di dalam Gua juga terdapat patung Tan Tik Siu karena beliau yang menguasai tempat tersebut. Maka masyarakat yang datang ke Gua harus menyembah Tan Tik Siu. Hal tesebut memiliki arti bahwa meminta izin sebelum memasuki Gua dari marabahaya yang ada. Selain itu terdapat patung dewi Kuan Im dan patung kuda yang juga memiliki peran sama yang perlu dilakukan oleh masyarakat sebagai bentuk awal melakukan ritual sebelum memasuki Gua Tan Tik Siu.

Nilai tingkah laku yang dapat diambil oleh masyarakat bahwa orang yang masuk dalam Gua Tan Tik Siu tidak boleh berkata dan berbuat yang jelek. Aturan tersebut dapat dibaca pada wawancara berikut:

"didepan gentong Sanepa terdapat tempat yang namanya Gandha Mayit. Nama tersebut hanya kiasan di dalam Gua tidak terdapat mayat tetapi istilah tersebut digunakan apabila masyarakat masuk Gua Tan Tik Siu harus seperti mayat, maksudnya tidak boleh rame, tidak boleh berkata jorok, dan harus melupakan segala hawa nafsu yang ada didalam dirinya". (wawancara dengan mbah Salam 12 Mei 2016).

Nilai abstraksi dari pengalaman tertentu berdasarkan keperccayaan dan tingkah laku, pantangan serta larangan di dalam Gua Tan Tik Siu tersebut yaitu sebagai wujud nyata yang telah terbukti bilamana melanggar perintah atau larangan yang menjadi nilai budaya.
Sekaligus disakralkan dengan kejadian yang sudah terjadi. Seperti di Gua Tan Tik Siu bilamana manusia ingin melihat nasib dapat menggunakan Jamsi. Hal tersebut dapat dilihat dari wawancara sebagai berikut:

"di depan foto Tan Tik Siu terdapat kotakkan kecil yang berjumlah 1 hingga 27 yang berisi doa-doa atau ramalan. Cara menggunakan Jamsi diaduk lalu diambil satu Jamsi yang telah jatuh. Setelah itu dicocokkan dengan tulisan yang ada di dalam kotakkan yang berjumlah 1 hinga 27. Lalu dibaca tulisannya: seandainya manusia ingin kaya harus bertapa brata, hemat, puasa senin kamis dsb. Maka orang yang percaya bakal terkabul dan orang yang tidak percaya tidak akan terkabul apa yang dia inginkan. (wawancara dengan Mbah Salam, 12 Mei 2016)

Selain terdapat jamsi juga terdapat patung macan yang merupakan simbol Nyai Roro Kidul dan juga patung Pagoda yang mempunyai simbol sembilan tingkatan jumlah wali pada Agama Islam (walisongo).

Nilai kehidupan masyarakat Sumberagung Gua Tan Tik Siu merupakan cikal bakal masyarakat Sumberagung karena asal mula desa sumberagung ada hubungannya dengan sumber mata air yang terdapat di desa tersebut. Sumber mata air yang menjadi satu-satunya di Sumberagung khususnya dusun kebon. Hal tersebut dapat dilihat dari wawancara berikut:

" konon, Tan Tik Siu sangat sakti. Dan sangat diakui oleh masyarakat sekitar. Karena dia mampu menutup sumber mata air terbesar yang menjadi cikal bakal nama desa yaitu Sumberagung. (sumber=mata air, Agung=besar). Yang menjadi satu-satunya pemasok air untuk danau atau rawa yang waktu itu memiliki 50 ribu hektar lebih yang merendam beberapa desa. Hal yang menakjubkan adalah Tan Tik Siu mau menutup sumber 
air besar tersebut hanya dengan menggunakan potongan putung rokok (utes) yang rokoknya terbuat dari ranting pohon yang sudah mengering. (wawancara dengan mbah Andhen 12 Mei 2016).

\section{Nilai Fungsi}

Menurut hasil penelitian legenda Gua Tan Tik Siu memiliki fungsi yaitu 1) sebagai sistem Proyeksi, 2) alat untuk mengesahkan pranata dan lembaga kebudayaan, 3) alat pendidikan anak, 4) memaksa norma-norma dan alat hiburan.

Sebagai sistem proyeksi yang terdapat di dalam Gua Tan Tik Siu berupa angan-angan Tan Tik Siu ketika beliau masih bertapa di Sendang Wilis Tulungagung untuk membangun gua Tan Tik Siu atau Gua Gondho Mayit di desa Sumberagung. Hal tersebut dapat dilihat dari wawancara sebagai berikut:

"sebidang tanah hadiah berukuran 60x40 meter kemudian di manfaatkan untuk membangun tempat ritual berupa bangunan mirip Gua Pendem dari beton yang sudah dirancang tatkala beliau masih bertapa di gunung Wilis. Gua ini memiliki nama Pasetra'an Gondho Mayit yang lebih dikenal dengan sebutan Tan Tik Siu. (wawancara dengan Mbah rejo 12 mei 2016)

Sebagai alat untuk mengesahkan pranata-pranata kebudayaan Gua Tan Tik Siu banyak didatangi massyarakat lokal dan daerah lain untuk ngalap berkah. Hal tersebut dapat dilihat dari wawancara sebagai berikut:

"paranormal yang datang tidak hanya dari Tulungagung saja, banyak dari Jogja, Solo, serta Banyuwangi. Tetapi saya juru kunci hanya bisa mengantar saja. Saya tidak mengerti apa-apa terhadap apa yang dilakukan masyarakat sekitar. Bagi kalangan spiritualis datang ditempat ini memiliki tujuan yang pada umumnya suka dengan keangkeran pertapaan Gondho mayit tersebut. Selain itu juga ingin ngalap berkah Tan Tik Siu. (wawancara dengan mbah Salam 12 mei 2016).

Sebagai alat pendidikan anak yaitu untuk melatih anak agar memiliki tingkah laku dan berbuat kebaikan. Dapat meniru prilaku Tan Tik Siu yang sopan, bijaksana dan bersahaja. Hal tersebut dapat dilihat pada wawancara berikut:

" peninggalan Tan Tik Siu alam dan isinya seperti: encok, Jimpe, pegel linu, cacing kremi, kandungan pendidikan alam dunia yaitu: Bremana, Bremani. Menghargai lima perkara yaitu panas, hujan, angin, debu, dan tanah. (wawancara dengan mbah Andhen 12 mei 2016)

Banyak sekali masyarakat yang percaya apabila ada masyarakat yang mencuri barang-barang yang ada di dalam Gua, wanita yang haid, tidak boleh berbicara yang jelek. Sebelum memasuki Gua harus memberi salam kepada Tan Tik Siu dengan cara: 1.)Kepada Tan Tik Siu yang menguasai tempat tersebut. 2) Kepada Dewi Kuan Im. 3)Dewa Jaran (kuda). 4) Dewa Pawon (dapur). Hal tersebut dapat dilihat pada wawancara berikut:

“ di depan Gua Tan Tik Siu terdapat Pohon asam yang sangat besar. Di dalam Gua Tan Tik Siu terdapat patung dewi Kuan Im yang bertujuan ketika memasuki Gua harus berdoa terlebih dahulu kepada Tan Tik Siu, Dewi Kuan Im, Dewa Jaran dan Dewa Dapur. Ketika pulang pun harus melakukan ritual yang serupa. (wawancara dengan Mbah Andhen 12 Mei 2016)

Sebagai fungsi alat hiburan yaitu yang dituturkan kepada anak-anak. Hal tersebut dapat dilihat dari wawancara sebagai berikut:

" pangeran Papak seorang anak kecil yang ikut mengembala, ketika waktu sore anak itu hilang tetapi ketika pagi hari anak itu selalu muncul. Selanjutnya dia menyuruh masyarakat sumberagung mencari batu yang banyak. Sementara 
masyarakat mencari batu, Tan Tik Siu pergi ke argo wilis sendang Tulungagung membuat Gua pertama di daerah sana. Setelah tiga tahun berlalu, Tan Tik Siu kembali ke desa sumberagung membuat Gua kedua dimana sebagai pekerja masyarakat Tulungagung pada tahun 1921. Setelah Gua tersebut selesai dibangun tahun 1921 Tan Tik Siu membuat perayaan semisal jaranan dan wayang. (wawancara dengan mbah Salam 12 Mei 2016).

\section{SIMPULAN}

Legenda Gua Tan Tik Siu merupakan cerita rakyat yang berwujud legenda yang memiliki ciri-ciri dan batasan berupa prosa rakyat yang dianggap pernah terjadi oleh masyarakat sekitar. Tokoh manusia biasa yang memiliki kesaktian seperti Tan Tik Siu. Legenda Gua merupakan salah satu genre sastra lisan yang memiliki cerita massyarakat pendukung berdasarkan tanggapan masyarakat dan analisis Gua Tan Tik Siu. Sebagai komposisi nilai budaya, legenda gua Tan tik siu memiliki nilai sistem kekerabatan masyarakat dan religi yang cukup kuat. Hal tersebut dibuktikan dengan adanya beberapa simbol-simbol yang terdapat di sekitar gua yang melambangkan nilai-nilai kehidupan dan pembelajaran sebagai bukti perlawanan terhadap penjajah pada saat itu.
Fungsi sosial dalam legenda tan tik siu adalah sebagai sarana dan prasarana cerita rakyat yang dituturkan secara turun temurun. Hal tersebut bermanfaat bagi keberlangsungan pembelajaran sejarah kearifan lokal di Indonesia khususnya di kabupaten Tulungagung.

\section{DAFTAR PUSTAKA}

Danandjaja, James. 1991. Folklor Indonesia Ilmu Gosip Dongeng dan lain-lain. Jakarta: Pustaka Grafiti.

Edraswara, Suwandi. DKK. 2006. Nilai Budaya Dalam Beberapa Karya Sastra Nusantara: Sastra Daerah di Kalimantan. Jakarta: Depdikbud Yogyakarta.

Edraswara, Suwandi. 2003. Metode Penelitian Sastra Lisan. Jakarta: PT Buku Kita. 2003. Metodologi Penelitian Sastra. Yogyakarta: Pustaka Widyatama.

2005. Tradisi Sastra Lisan. Yogyakarta. Narrais.

Hutomo, Suripan Sadi. 1991. Mutiara Yang Terlupakan. Surabaya: Hiski.

Hutomo, Suripan Sadi. 2001. Sinkretisme Jawa Islam. Yogyakarta: Yayasan Bentang Budaya.

Koentjaraningrat. 2005. Pengantar Antropologi. Pokok-pokok Etnografi. Jakarta: Djambatan

Yuwana Sudikan, Setya. 2001. Metode Penelitian Sastra Lisan. Surabaya: Citra Wacana. 